\title{
La escritura del proyecto arquitectónico Y la relación tridimensional de sus signos*
}

\author{
Writing of the architectural design \\ and the tridimensional relation of its signs
}

A escritura do projeto arquitetônico e a relação tridimensional de seus signos

Fecha de entrega: 5 de noviembre de 2014 Fecha de evaluación: 25 de noviembre de 2014 Fecha de aprobación: 15 de diciembre de 2014

Theodora Papidou**

\section{Resumen}

En el presente texto, el proyecto arquitectónico se considera respecto a las líneas trazadas y las palabras escritas de su proceder. Estas huellas escritas del proyecto, que aparecen en su dualidad, condensan un pensamiento que pertenece exclusivamente a la arquitectura y a su proyectar. El estudio de los signos de esta doble escritura proyectual

* Las partes de este artículo provienen de la tesis doctoral de la autora, titulada: El proyecto arquitectónico y su espacio de inscripción, presentada en la Universidad Politécnica de Cataluña, Escuela Superior de Arquitectura de Barcelona, el 4 de junio de 2014. Director de la tesis: Juan José Lahuerta Alsina.

* Arquitecta, Doctora en Teoria e Historia de la Arquitectura por la Universidad Politécnica de Cataluña (ETSAB, Barcelona 2014), ha participado en programas de investigación sobre la teoria del proyecto arquitectónico y la semiótica del arte. Sus trabajos de investigación se centran en la relación entre escritura y arquitectura. Correo electrónico:dp_arch@hotmail.com. 
arquitectónica nos permite un acceso a este particular pensar. En vez de la dialéctica entre lo icónico y lo verbal, la presente aproximación al proyecto arquitectónico considera los signos de la doble escritura sistemáticamente como una unidad de significancia cuya interpretación se halla en algo fuera del logos; se halla en el lugar de la obra arquitectónica. El concepto del signo de Charles S. Peirce, en tanto que relación tridimensional entre tres factores, nos permite asignar a los signos de la doble escritura una interpretación.

Palabras clave: proyecto arquitectónico, escritura, inscripción, gesto, signo, lugar.

\section{Abstract}

In this paper, the architectural project is considered regarding the lines drawn and the words written from where they come. These written traces of the project, that appear in its duality, condense a though that belongs exclusively to architecture and its design. The study of the signs in this double writing of architectural design allows an access to this specific thinking. Instead of the dialectic between the iconic and the verbal, this approach to the architectural project considers the signs of double writing systematically as a significance unit whose interpretation is found in something outside the logos; it is in the place of the architectural work. The concept of sign of Charles S. Peirce, while three-dimensional between three factors, allows us to assign to the signs of the double writing an interpretation.

Keywords: Architectural design, writing, inscription, gesture, sign, loci.

\section{Resumo}

No presente artigo consideramos o projeto arquitetônico a partir das linhas traçadas e das palavras escritas, as quais se remetem ao seu planejamento. Estas marcas deixadas pela escrita do projeto, que aparecem nessa dualidade, condensam um pensamento que pertence exclusivamente à arquitetura e à ação de projetar. $\mathrm{O}$ estudo dos signos desta dupla escritura do projeto arquitetônico nos permite acessar essa 
particular forma de pensar. Em vez da dialética entre o icônico e o verbal, a aproximação ao projeto arquitetônico considera os signos da dupla escritura sistematicamente como uma unidade de significância cuja interpretação se encontra fora do logos; está presente no lugar da própria obra arquitetônica. O conceito de signo de Charles S. Peirce, sobre os três fatores da relação tridimensional, nos permite atribuir aos signos da dupla escritura uma interpretação.

Palavras-chave: Projeto arquitetônico, escritura, inscrição, gesto, signo, lugar.

\section{El espacio de inscripción. Una introducción}

El arquitecto en cada momento de proyectar tiene a su disposición obviamente dos maneras de presentar por escrito lo pensado-imaginado: la representación visual y la expresión verbal. Como los cuadernos de dibujos y notas de la mayoría de los arquitectos demuestran, lo espacialmente configurado y lo verbalmente articulado, estas dos distintas maneras de expresión, se encuentran en un mismo sitio: sobre la misma hoja de papel. Un trazo indeterminado y una palabra escrita al principio suelta se encuentran en un sitio común y esta esencial con-(dis)posición pone en marcha la maquinaria interpretativa de encontrar referencias, inventar correspondencias o construir similitudes.

En vez de estudiar las interrelaciones entre las más viejas e irreconciliables oposiciones entre el mostrar y el nombrar, entre el figurar y el decir, el lugar común donde las líneas y las palabras convergen exige al proyecto arquitectónico determinarse más allá de la neutralidad de cualquier soporte material de fijación. Sobre la superficie del papel, las líneas y las palabras se retienen, pero ellas se inscriben por esencia en un medio de otro orden, y se con-ponen precisamente gracias a ello. Ese medio determina las interrelaciones entre las líneas y las palabras del doble gesto inicial de fijar lo pensado-imaginado, desplazándolas desde una simple referencia o correspondencia de una a otra hacia otras regiones, donde las palabras dejan de designar estrictamente lo trazado y las líneas dejan de reproducir directamente lo escrito en imagen.

Ese medio franqueado por las líneas y las palabras del proyecto arquitectónico adquiere las dimensiones de un espacio particular, que ha sido denominado como espacio de inscripción (Papidou, 2014). En este espacio la representación y la descripción se 
suspenden merced a la indicación esencial de lo trazado y lo escrito hacia las afueras de lo gráfico, hacia el espacio arquitectónico.

El gesto de trazar una línea y el gesto de escribir una palabra esconde una fijación esencial: la escritura. Esa fijación esencial del pensamiento en algo material ${ }^{1}$ contie- $^{-}$ ne siempre en su interior una inscripción. El espacio de inscripción siendo el fondo desde el que es y se piensa el proyecto arquitectónico, abre una nueva interpretación de las líneas trazadas y las palabras escritas basada en una concepción de la escritura considerada como origen del sentido en sí (Papidou, 2014, pp. 105-112).

La aproximación al proyecto arquitectónico a partir de la escritura, aparta el discurso acerca de la arquitectura de toda dirección transcendental. En vez de ello, en vez de enfocarse en la "materialidad fugaz" de la idea, nos ocupamos de la materialidad primaria del proyecto, de lo yacente en ello: de lo que se ha denominado la doble escritura del proyectar arquitectónico (Papidou, 2014).

La presente aproximación al proyecto arquitectónico sostiene que ambos gestos, el de trazar en líneas y el de escribir en palabras, aunque ontológicamente incompatibles y en parte complementarios, para el proyecto arquitectónico forman una única operación de fijar el pensamiento propiamente arquitectónico. Por consiguiente, el estudio de la doble escritura nos puede proporcionar una herramienta para describir e interpretar el proyecto arquitectónico en otros términos a los que la retórica espontánea de la forma y del discurso determina. En vez de las modificaciones de la forma sostenidas por un discurso que las interpreta, los signos de la doble escritura se consideran sistemáticamente como una misma unidad de significancia, ya sean signos icónicos o verbales, respecto a un horizonte interpretativo que pertenece a la arquitectura y al proyecto arquitectónico.

\section{El gesto y el signo}

El gesto consiste en la expresión más elíptica y rudimentariamente materializada de la intencionalidad. Es la primaria y elemental apariencia "material” de la intencionalidad en tanto que sonido, gesticulación, marca; es aquello que puede abrir en el correlato

1 La escritura es "la aptitud para fijar el pensamiento mediante simbolos materiales" (Leroi-Gourhan, 1971, p. 185). Hay que subrayar que el "fijar el pensamiento" no tiene el sentido de un "fosilizar el pensamiento", sino que es un asegurar el pensamiento en su movilidad. El que se fija en el escribir se dicta desde la esencia del pensar. 
entre mente-mundo un nuevo espacio, anunciando de esta manera la institución de un nuevo código interpretativo.

La intencionalidad, esa "propiedad general de una mente, a diferencia de los vegetales y de los seres simplemente físicos, de "salir al exterior"” (Lobo, 1999, p. 17) es la que abre la mente al mundo y el mundo a la mente dando la posibilidad de un acto $^{2}$ en el mundo: escribir, mostrar, construir. Entre ellos, el gesto gráfico constituye el gesto previo a la institución del lenguaje y de la escritura, del arte y de la arquitectura; el gesto previo, cada vez, a cualquier código interpretativo ${ }^{3}$. Como fundamento común y origen de todo simbolismo se encuentra el gesto gráfico que anuncia, en el correlato de la mente con el mundo, la fundación de un nuevo mundo fijado en signos.

Para el proyecto arquitectónico, las líneas y las palabras, aunque sean trazadas sobre el papel, cobran su ser-signo en el momento de su inscripción en el mundo material y desde ahí adquieren una nueva dirección en el mundo de significación. Las líneas trazadas y las palabras escritas actúan, en general, como gestos de una realidad interior y siendo escritas actúan como signos que indican lo que todavía no ha conseguido fijarse en diagramas y conceptos, en imágenes y discursos; actúan como signos que indican aquello que todavía no ha sido fijado en la obra arquitectónica misma.

2 El gesto es, según George Mead, como "una etapa primitiva del acto" (1991, p. 181). El acto es en sí positividad, demostración y efecto de la intencionalidad: "un acto es lo que puede ser realizado o efectuado, segmentado, recuperado, mantenido, suspendido; el acto es el "yo puedo" del "yo pienso"'" (Ricoeur, 1988, p. 145).

3 Escribe Edmund Husserl: "estas exteriorizaciones (Äusserungen) [gestos, ademanes] no son expresiones en el sentido de discurso (Rede); no están, como las expresiones, unidas en unidad fenoménica con las vivencias exteriorizadas, en la consciencia del que las exterioriza; en ellas no comunica uno a otro nada; al exteriorizar estas manifestaciones fáltale al sujeto la intención de presentar unos "pensamientos" en modo expresivo (in ausdrücklicher Weise), ya a otros, ya a si mismo, en cuanto que se halle solo consigo mismo" (Derrida, 1995, pp. 80-81). Jacques Derrida explica más adelante: "los signos no expresivos no quieren decir (bedeuten) más que en la medida en que se les pueda hacer decir lo que se murmuraba en ellos, lo que se queria decir en una especie de farfulleo. Los gestos no quieren decir más que en la medida en que se los puede escuchar, interpretar (deuten)" (1995, p. 81).

4 "Un mundo no es una mera agrupación de cosas presentes contables o incontables, conocidas o desconocidas. Un mundo tampoco es un marco únicamente imaginario y supuesto para englobar la suma de las cosas dadas. Un mundo hace mundo [Welt weltet] y tiene más ser que todo lo aprensible y perceptible que consideramos nuestro hogar. Un mundo no es un objeto que se encuentre frente a nosotros y pueda ser contemplado. Un mundo es lo inobjetivo a lo que estamos sometidos mientras las vias del nacimiento y la muerte, la bendición y la maldición nos mantengan arrobados en el ser" (Heidegger, 1996, pp. 31-32). 
Enfoquemos en el concepto de signo en búsqueda de un sustento semiótico para asignar a los signos de la doble escritura una interpretación.

Por definición, el signo es siempre portador de significación. Como no existe per se sino solo se piensa y se es desde una mente, es a través de una operación de reducción merced a la cual se suspende lo inmediata y naturalmente dado, mientras aparece el dominio del sentido. Pero, para que un concreto actúe "como" signo debe ser signo de algo diferente de ello mismo. "El papel del signo es representar, ocupar el puesto de otra cosa, evocándola a título de sustituto" (Benveniste, 2002, pp. 54-55). Y sustitución significa distraerse de sí mismo, no ser por sí mismo, es decir “absolutamente próximo de sí (prope, proprius)" (Derrida, 2003, p. 64), siendo en el mismo momento algo concreto y sensible.

El signo señala una ausencia (Ducrot y Todorov, 1974, p. 124). Es como un equivalente visible $^{5}$ de algo ausente, de algo que no se manifiesta en sí mismo.

Según la "faneroscopia" o "fenomenología" de Peirce, la manifestación en sí misma no revela una presencia, sino que constituye un signo. Se puede leer en los Principles of phenomenology que "la idea de manifestación es la idea de un signo" (Derrida, 2003, p. 64)

En la fenomenología heideggeriana, por el contrario, "la idea de manifestación" coincide con el concepto del fenómeno. "Lo que se muestra en sí mismo, lo patente" es lo que Heidegger denomina fenómeno frente a la "estructura básica formal” del aparecer, la cual rige "todos los indicios, signos, síntomas y símbolos [...] por distintos que sean entre sí" (Heidegger, 1944, pp. 39-40). Concluye Heidegger que "los

5 "En el dominio de las lenguas indoeuropeas y entre estas, en especial, en griego, latín y alemán, las raices de los dos grupos principales de palabras con significación de signo aluden al campo de lo visible" (Bühler, 1979, p. 56). Acerca de la noción del signo y de su etimología Walter Ong escribió más detalladamente: "Signo" se refiere fundamentalmente a algo percibido de manera visual. Signum, que nos dio la palabra "signo", significaba el estandarte que una unidad del ejército llevaba en alto como identificación visual; etimológicamente, el "objeto al que se sigue" (raiz protoindoeuropea, sekw-seguir). A pesar que los romanos conocian el alfabeto, este signum no era una palabra escrita con letras sino una especie de enseña o imagen dibujada, como un águila, por ejemplo" (2002, p. 79).

6 "Lo que señala por lo regular la familia de las palabras-signos indoeuropeas en sus diversas raices es el mostrar (descubrir) las cosas al espectador $\mathrm{O}$, a la inversa, el conducir al espectador (a la mirada espectadora) hacia las cosas" (Bühler, 1979, p. 56). 
fenómenos no son nunca apariencias, pero en cambio toda apariencia necesita de fenómenos" (1944, p. 39), dando la siguiente explicación:

La apariencia en cuanto apariencia "de algo" no quiere justamente, decir [...] mostrarse la cosa misma, sino el anunciarse algo que no se muestra por medio de algo que se muestra. Aparecer es un no-mostrarse. [...] Aparecer es el anunciarse por medio de algo que se muestra (1944, p. 40).

Aparte de las dos direcciones divergentes acerca del signo procedentes de la fenomenología y de la semiótica, el lugar común para el fenómeno y el signo es la función de remitir, con independencia a cómo se realiza tal remisión, o sea mediante el "mostrarse en sí mismo" o el "anunciarse por medio de algo que se muestra". Y esta función es propia de los signos, de los fenómenos, como lo es propia de las cosas en general, sin que ello signifique que los signos sean simplemente cosas sin nada más. Es precisamente esa función, que Carlo Sini denomina "el remitir ontológico del signo" (1989, p. 22), la que pone en relación la experiencia común con el mundo de la significación. Sini cita a la siguiente definición del signo por Heidegger: "los signos son en primer lugar medios, cuyo carácter específico de medio consiste en el indicar" (1989, p. 23). Y lo que se señala "por medio de una indicación" (Heidegger, 1994, p. 117) es aquel pensamiento que quiere ser rescatado -el "señalar es un rasgo fundamental del pensar", escribe Heidegger- o que, en otros términos, pone en marcha un procedimiento interpretativo, la semiosis infinita de Peirce ${ }^{7}$.

Lo que Benveniste insinúa cuando escribe que todos los signos, en general, "parecen engendrarse y multiplicarse en virtud de una necesidad interna, que en apariencia responde también a una necesidad de nuestra organización mental" (2002, p. 55), Peirce lo define con precisión cuando ya introduce en el signo este movimiento del pensamiento hacia otro pensamiento (futuro) más desarrollado:

Un signo es algo que es relacionado con una segunda cosa, su objeto, desde cierto aspecto o cualidad, de tal manera que lleva a una tercera, su interpretante, a una relación con el mismo objeto, y esto de tal manera, que aquel [el

7 En la semiótica de Peirce, es importante subrayar que en la base de la definición del signo se hallan una serie de relaciones triádicas que señalan explicitamente el movimiento y la dirección propia de la función sígnica. En concreto, por "semiosis" se entiende una acción o influencia la cual es o implica la cooperación de tres sujetos, como un signo, su objeto, y su interpretante. Y esta influencia no puede de ninguna manera ser resuelta en acciones entre pares. 
interpretante] lleva a un cuarto a una relación en el mismo sentido con el objeto, y así ad infinitum (1932, 2.92).

De hecho, en Peirce, frente a la semiología saussuriana, el signo es una relación dinámica (genuina) entre tres polos: el Representamen ${ }^{8}$ o simplemente signo (la cualidad material del signo), el Objeto (la cosa denotada) y el Interpretante (el "respecto" bajo el cual es posible instituir un signo -código en otros términos-). Se incluye, por tanto, en el signo mismo el efecto -que suscita su función sígnica-, es decir el Interpretante que puede ser simplemente mental, lógico-lingüístico o institucional.

Ahora bien, enfoquemos primero en los signos verbales, aquellos signos que pertenecen al sistema de signos llamado lengua. En la semiótica de Peirce, los signos verbales respecto a su objeto denotado pertenecen, en su mayoría, a aquella subespecie del signo llamado símbolo. Según Peirce, el símbolo es el símbolo aristotélico, por definición convencional. Eso quiere decir que la relación entre la cara sensible del signo (la sucesión de las letras en las palabras) con lo simbolizado (el significado de la palabra) no tiene ninguna relación por semejanza o ninguna conexión causal, sino que es una relación instituida y por tanto convencional, basada en un código preexistente que en el caso de los símbolos verbales es la lengua. También, las palabras en la analítica de Peirce, respecto al efecto que provocan a una mente, son la primeridad del Interpretante lógico-lingüístico (según la tricotomía: palabra-juicio-discurso), es decir son un posible algo, la posibilidad de un signo interpretante. Cuanto más desarrollado es un signo interpretante, puede ser luego un juicio (frase) y al final un discurso (silogismo).

Por otra parte, también en la semiótica de Peirce, los signos que pueden significar algo, en general por su forma, constituyen una determinada categoría de signos llamados íconos. Según el tipo de la semejanza, los íconos se dividen en imágenes que representan su objeto a través de la semejanza pura y simplemente icónica, en diagramas a través de la analogía y en metáforas a través del paralelismo establecido entre el signo y su objeto. Mientras el Interpretante último es lógico-lingüístico y las

8 "La denominada "cosa misma" es desde un comienzo un representamen sustraído a la simplicidad de la evidencia intuitiva. El representamen solo funciona suscitando un interpretante que se convierte a su vez en un signo y así hasta el infinito. La identidad consigo mismo del significado se oculta y desplaza sin cesar. Lo propio del representamen es ser él y otro, producirse como una estructura de referencia, distraerse de si" (Derrida, 2003, p. 64). 
palabras ya de por sí corresponden a la primeridad del Interpretante, en el caso de los signos icónicos no sucede lo mismo. De hecho, lo que aquí vale considerar es si puede existir otro tipo de interpretación que no sea efectivamente articulada en discurso.

Aunque "precisamente sobre la interpretación se funda la posibilidad del lenguaje y de la palabra, es decir, la posibilidad de la articulación lingüística", sin embargo, "la interpretación articula sin recurrir propiamente a juicios (al logos)" comenta Carlo Sini (1989, p. 30) citando a Heidegger: "la carencia de palabras no significa la carencia de una interpretación” (Sini, 1989, p. 23). Se puede sostener que la interpretación articula porque elige cada vez una determinada perspectiva (Sini, 1984, pp. 28-29) hacia aquello que se debe interpretar, y es aquello mismo el que pro-yectando su ser permite la interpretación. En el proyecto, por tanto, el horizonte hermenéutico, donde lo que se debe interpretar (las líneas y las palabras de la escritura proyectual) en tanto que pro-yectado y nuestra comprensión se aproximan, es el espacio de inscripción, mientras esa perspectiva, como se explica a continuación, es de índole espacial.

\section{La "interpretabilidad peculiar" de los signos de la doble escritura}

El espacio de inscripción, aunque es principalmente un espacio franqueado por el gesto gráfico, ocupa un campo intersticial entre dos órdenes espaciales, el mental y el pragmático. Su condición de estar "entre" implica una operación de ensanchamiento de los límites de lo gráfico. Y ensanchar los límites de lo gráfico significa lanzar lo gráfico hacia sus extremidades, donde el salir hacia sus afueras casi resulta innecesario. En sus fronteras con el espacio pragmático y durante esa operación de lanzamiento del campo gráfico hacia sus extremidades, es donde algo extra-gráfico, como se explica a continuación, aparece en escena.

Aquel algo extra-gráfico, que distorsiona ligeramente los límites infranqueables de lo gráfico, no es algo secundario. De hecho, ese algo permite el vínculo de la doble escritura con la obra proyectada y, aunque exterior a lo gráfico, es inmanente y propio a la interioridad del proyectar, por ser determinante para el juego de remisiones entre la doble escritura y la obra proyectada. Ese algo extra-gráfico es propiamente el lugar y es "el respecto a", el factor determinante respecto a lo intra-gráfico y su retención en signos. 
De esta manera, el lugar no es el contexto ni el conjunto de datos presentes que organizan el entorno del solar, sino que contiene la potencia de articular en términos espaciales lo que ha sido denominado unidad (Papidou, 2014, pp. 183-189) entre las distintas operaciones del gesto proyectual arquitectónico; contiene la potencia de articular la unidad entre el trazar, denominar, inscribir y edificar, la unidad recuperada merced al espacio de inscripción.

Se puede sostener que el lugar es el mediador entre el texto proyectual y la obra proyectada (esquema) en el sentido de un intérprete -Interpretante ${ }^{9}$ en la semiótica de Charles S. Peirce- quien, al contrario que un traductor de un texto que debe exaltar el original, trasplantándolo a otro idioma, afirma que lo que alguien quiere decir, y no lo que efectivamente dice, es lo que él mismo (el intérprete) está diciendo. El lugar, en su papel de "intérprete", garantiza que aquello que el texto proyectual "quiere-decir" sea trasmitido a la obra proyectada, o en concreto, garantiza que lo que quiere-serfijado quede asegurado en el texto proyectual.

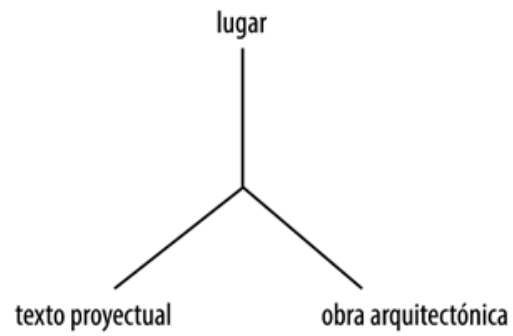

Figura. Lugar: la perspectiva que hace posible la institución de una relación sígnica entre el texto proyectual y la obra arquitectónica.

9 Según Peirce, el signo es una relación dinámica entre tres polos: el Representamen o simplemente signo, el Objeto y el Interpretante. Si aplicamos este modelo triádico al procedimiento proyectual entonces el texto proyectual sería el Representamen cuyo Objeto sería la obra proyectada y el Interpretante sería el lugar. Respecto a ese último: "[...] toda comparación exige, además de la cosa referida, el fundamento, el correlato, es decir: una representación mediadora que representa que el relato es una representación del mismo correlato que esa misma representación mediadora representa. Tal representación mediadora puede ser llamada interpretant, porque satisface el oficio del intérprete, quien dice que un extranjero dice la misma cosa que él está diciendo" (Peirce, 1997, pp. 308-309). 
El Interpretante, que no es solo la mente o el pensamiento ${ }^{10}$, es, según Peirce, el significado operativo de la relación semiótica en cuanto relación tridimensional o semiosis entre un signo (Representamen), su Objeto y su Interpretante. Por semiosis se entiende "el proceso en el que algo funciona como signo" (Morris, 1985, p. 27), proceso que implica una relación tridimensional, es decir, una relación dinámica entre tres factores que en ningún caso puede acabar en una relación de parejas. Ahora bien, la semiosis no se entiende de forma abstracta, "sino de manera concreta, como configuración simbólica de la multiplicidad dinámica de la experiencia, que el signo intenta "captar" y “detener”" (Bentolila, 2008). En una tal operación, el Interpretante actúa como elemento configurante de aquello que es captado y detenido por el signo, mientras en el juego de remisiones entre el Interpretante y el Representamen emerge la naturaleza del signo "en su esencia más profunda” (Sini, 1989, p. 49).

Por consiguiente, el lugar como Interpretante del procedimiento proyectual interpreta de manera peculiar los signos gráficos ${ }^{11}$ al manifestar "el "respecto" y la "capacidad" (ground), bajo los cuales es posible instituir una relación sígnica” (Sini, 1989, p. 57), en concreto, la relación entre los signos de la doble escritura (Representamen) y la obra diseñada (su Objeto). El lugar, por lo tanto, es la "perspectiva"12 que hace posible la interpretación de los signos gráficos. Es la "interpretabilidad peculiar"13 del texto

10 Charles Morris, en sus Fundamentos de la teoría de los signos, hace implícita la distinción entre el Interpretante y el Intérprete el cual enumera como el cuatro factor de la semiosis (1985, p. 27).

11 El signo en relación al Interpretante: "[...] es la respuesta a la pregunta: ¿cómo se especifica el espacio de respuesta al signo, el lugar de su interpretación? No en cambio: ¿quién interpreta? Esta es una pregunta no originaria: "quién" o "qué" interpreta es solo un caso "encarnado" de Interpretante; la cuestión es, en cambio, la del abrirse del lugar de la interpretación, según las tres categorias faneroscópicas" (Sini, 1989, p. 56).

12 "El "respecto y la capacidad" de la definición del signo de Peirce equivale a la "perspectiva" (ya implícita en cada pre-comprensión) de Heidegger. Lo que significa que también en Peirce funciona el "círculo hermenéutico": existe una asunción preliminar, una perspectiva, que hace posible la interpretación. El acaecer del evento (del significado) es entonces propiamente el acaecer de la perspectiva, o sea, del ground: terreno, espacio, lugar de la interpretación. Pero este es también el acaecer del lugar del mundo o, mejor dicho, del lugar del ser-en-el-mundo" (Sini, 1989, p. 57).

13 Según Peirce, tres son las clases del Interpretante: el Interpretante Inmediato, el Interpretante Dinámico y el Interpretante Final. "Mi Interpretante Inmediato está implícito en el hecho de que cada Signo debe tener su Interpretabilidad peculiar antes de obtener un Intérprete. Mi Interpretante Dinámico es aquel que es experimentado en cada acto de interpretación, y en cada uno de estos es diferente de cualquier otro; y el Interpretante Final es el único resultado Interpretativo al que cada Intérprete está destinado a llegar si el Signo es suficientemente considerado. El Interpretante Inmediato es una abstracción: consiste en una Posibilidad. El Interpretante Dinámico es un evento singular y real. El Interpretante Final es aquel hacia el cual tiende lo real" (Peirce, 1987, p. 146). 
proyectual, la posibilidad de interpretación aludiendo a una condición-articulación espacial que todavía no es mostrada, ni mucho menos está fijada en la realidad.

Aquello no-mostrado es lo que quiere-ser-fijado en tanto a lugar (Papidou, 2014). Como una especie de idea desdibujada, persiste en mantenerse activa durante el procedimiento proyectual, determinando la manera que los signos del texto proyectual remiten a la obra proyectada. Lo que quiere-ser-fijado en tanto a lugar es el fundamento del proyectar. Es aquella abstracción ${ }^{14} o$ idea $^{15}$-ground (fundamento, base o terreno) en la semiótica de Peirce-, merced a la cual los gestos de expresar, figurar, marcar y edificar, son llevados a la unidad ${ }^{16}$. Lo que quiere-ser-fijado en tanto a lugar, por tanto, convoca en unidad a la multiplicidad de operaciones del gesto proyectual, unidad que los signos de la doble escritura intentan "captar" y "detener", y por otra parte convoca en unidad al texto proyectual -lo yacente del espacio de inscripcióncon la futura inscripción in situ.

Mantener los signos gráficos, potencialmente activos respecto a la direccionalidad promovida por aquello que quiere-ser-fijado en tanto a lugar, significa interpretar el texto proyectual sin buscar el fundamento en códigos y simbolismos pre-establecidos, y sin acudir a la detección de los procesos psíquicos-imaginativos del arquitecto. Por tanto, lo que quiere-ser-fijado en tanto a lugar es la condición habilitante para asignar a los signos de la escritura proyectual una interpretación, que no sería promovida

14 Peirce dio una explicación respecto al concepto de fundamento: "no podemos comprehender un acuerdo de dos cosas, excepto como un acuerdo en algún respecto, y este respecto es una pura abstracción. [...] Tal abstracción pura, la referencia a la cual constituye una cualidad o atributo general, puede ser llamada un fundamento o base" (1997, pp. 307-308).

15 En otra ocasión, Peirce describe el fundamento como una idea: "el signo está por algo: su objeto. Está por ese objeto no en todos los aspectos, sino en referencia a una especie de idea, a la que a veces he llamado fundamento [ground] del representamen" $(1932,2.228)$.

16 Es importante incluir aqui el siguiente extracto de Charles S. Peirce, donde se describe el rol del interpretante, y por consiguiente, el rol del lugar en el caso de proyectar: "la referencia a un interpretant se hace posible y se justifica por aquello que hace posible y justifica la comparación. Pero eso es claramente la diversidad de impresiones. Si no tuviéramos más que una impresión, no se requeriría reducirlas a la unidad, y no se necesitaría por lo tanto ser pensadas como referidas a un interpretante, y la concepción de la referencia a un interpretant no surgiría. Pero dado que hay una multiplicidad de impresiones, tenemos un sentimiento de complicación o confusión, que nos lleva a diferenciar esta impresión de aquella, y luego, habiendo sido diferenciadas, requieren ser llevadas a la unidad. Ahora bien, no son llevadas a la unidad hasta que no las concebimos juntas, como nuestras, es decir, hasta que no las referimos a una concepción como su interpretant" (1997, p. 309). 
desde la intención declarada del arquitecto-diseñador, ni mucho menos desde estilos o tendencias arquitectónicas preexistentes.

Aunque al final esa idea no llegue a retenerse integralmente, desvela facetas insospechadas de lo real, siendo la clave (Andacht, 1996) que abre a los signos gráficos una serie (capas) ilimitada de "lugares". Estos "lugares" son esencialmente utópicos, porque llevan implícitamente lo que quiere-ser-fijado que no es otro que una idea cada vez determinada de habitar. Sin perder la direccionalidad promovida por esa idea, los signos del texto proyectual señalan esa multiplicidad de posibles lugares, más allá del contexto de su aparición, es decir, de los datos presentes del sitio.

El fundamento, como ha sido descrito anteriormente y estando entre el texto proyectual, la obra y el lugar, funciona como un "operador lógico" que elige, entre la infinitud de posibilidades, aquel aspecto según el cual podemos acudir a la significación. Y qué significa el término significar ${ }^{17}$ si no la traducción, como explica Levi-Strauss, "a un lenguaje diferente", el salto o reducción, podríamos sostener, de un material "a un nivel diferente" (1987, pp. 30-31). Y la búsqueda de la significación, ¿acaso no sería la búsqueda de aquel territorio de discontinuidades en donde se cruzan las direcciones de estas reducciones a otros niveles? Donde se busca, por lo tanto, una significación específicamente arquitectónica y es precisamente procedida del juego de remisiones y saltos entre las tres dimensiones: texto proyectual, obra y lugar. Y lo que sustenta ese territorio de discontinuidades es aquello que quiere-ser-fijado en tanto a lugar: una idea determinada de habitar.

\section{Sinopsis}

En el proyecto arquitectónico, el doble gesto de trazar en líneas y escribir en palabras tiene miras por esencia hacia su exterior, hacia la efectiva inscripción de sus marcas en un sitio. Se puede sostener que los signos de la doble escritura por un lado, expresan, aunque al principio no con plenitud, lo pensado o lo imaginado, y por otro lado, indican aquello que todavía no ha sido fijado tanto en el papel como en la obra arquitectónica misma. Por lo tanto, los signos de la doble escritura no funcionan

17 "La semiótica no se fundamenta en una teoria del "significado", pero el término "significado" ha de clarificarse en términos semióticos" (Morris, 1985, p. 89). Y también: "los significados no han de situarse como existencias en cualquier lugar en el proceso de semiosis sino que han de caracterizarse en términos de este proceso globalmente considerado" (Morris, 1985, p. 90). 
como expresión del idiolecto del arquitecto sino que remiten a la inscripción mundana, remiten al espacio arquitectónico señalando, de este modo, la extensibilidad del espacio de inscripción fuera del horizonte hermenéutico.

Los signos de la doble escritura, pues, remiten a la inscripción mundana y al espacio arquitectónico, mientras aquello que determina su fijación es el lugar; o más en preciso es una cierta idea cada vez de habitar, que persiste en mantenerse activa durante el procedimiento proyectual. Esta idea de habitar, en principio desdibujada, puede ser precisada como aquello que quiere-ser-fijado en tanto a lugar. Esa idea de habitar que persiste en mantenerse activa durante el procedimiento proyectual es la condición habilitante para asignar a los signos de la escritura proyectual una interpretación. En otras palabras, el lugar y aquello que quiere-ser-fijado en tanto a lugar es la "perspectiva" que hace posible la institución de una relación sígnica entre el texto proyectual y la obra arquitectónica.

\section{Referencias}

Andacht, F. (1996). El lugar de la imaginación en la semiótica de C. S. Peirce. En Anuario Filosófico, 29(3). Disponible en http://www.unav.es/gep/AF/Andacht. html.

Bentolila, H. (2008). Signo y movimiento en el pensamiento de Charles S. Peirce. In Peirce en Argentina [III Jornadas GEP]. Disponible en http://www.unav.es/gep/ IIIPeirceArgentinaBentolila.html

Benveniste, E. (2002). Problemas de lingüística general. Vol. II. México: Siglo XXI.

Bühler, K. (1979). Teoría del lenguaje. Madrid: Alianza.

Derrida, J. (1995). La voz y el fenómeno. Introducción al problema del signo en la fenomenología de Husserl. Valencia: Pre-Textos.

Derrida, J. (2003). De la Gramatología. México: Siglo XXI.

Ducrot, O., y Todorov, T. (1974). Diccionario Enciclopédico de las ciencias del lenguaje. Buenos Aires: Siglo XXI.

Heidegger, M. (1944). El Ser y el Tiempo. Madrid: Fondo de Cultura Económica. 
Heidegger, M. (1996). El origen de la obra del arte. En Caminos de bosque. Madrid: Alianza.

Leroi-Gourhan, A. (1971). El gesto y la palabra. Caracas: Ediciones de la Biblioteca de la Universidad Central de Venezuela.

Lévi-Strauss, Cl. (1987). Mito y significado. Madrid: Alianza.

Lobo, F. (1999). Teoría del conocimiento: Ética y Estética [transcripción de lecturas impartidas en ETSAB, UPC, Barcelona].

Mead, H. G. (1991). La génesis del self y el control social. Revista Española de Investigaciones Sociológicas, (55), 165-186.

Morris, Ch. (1985). Fundamentos de la teoría de los signos. Barcelona: Paidós.

Ong, W. J. (2002). Oralidad y escritura. México: Fondo de Cultura Económica.

Papidou, T. (2014). El proyecto arquitectónico y su espacio de inscripción. (Tesis doctoral). Barcelona: Universidad Politécnica de Catalyña. Disponible en la base de datos TDX: http://hdl.handle.net/10803/279249

Peirce, Ch. S. (1932). Collected Papers of Charles Sanders Peirce. Volumes I and II: Principles of Philosophy and Elements of Logic. Ch. Hartshorne and P. Weiss, (eds). Cambridge M.A: Harvard University Press.

Peirce, Ch. S. (1987). Obra lógico-semiótica. Madrid: Taurus.

Peirce, Ch. S. (1997). Sobre una nueva lista de categorías. En Escritos filosóficos. Vol. I. Zamora: El Colegio de Michoacán.

Ricoeur, P. (1988). El discurso de la acción. Madrid: Cátedra.

Sini, C. (1989). Pasar el signo. Madrid: Mondadori. 